\title{
SUBORDINACIÓN LOCAL AL MANEJO TERRITORIAL GLOBALIZADO DE LA RIBERA DEL LAGO DE CHAPALA
}

\section{Local Subordination to Globalized Territorial Management of the Chapala Lake}

\author{
ADRIANA HERNÁNDEZ - GARCÍA*
}

Fecha de recepción: 17 de febrero de 2017 - Fecha de aprobación: 11 de abril de 2017

\section{Resumen}

El presente artículo aborda el proceso de reapropiación del lago de Chapala, México. En las últimas décadas se han venido transformando el suelo y la producción agrícola en los municipios ribereños del lago de Chapala debido a la introducción de cultivos de exportación mediante sistemas modernos de producción tecnificada. Por lo que los cultivos tradicionales han ido disminuyendo o se producen con mayor uso de pesticidas, fertilizantes y agroquímicos. El papel del campesino ribereño también se ha modificado debido a que las agroempresas trasnacionales generan una estructura de renta o compra de suelos y parcelas que utilizan durante un periodo de años, perdiendo el dueño el uso de sus tierras a cambio de un ingreso seguro. En el escenario ribereño actual, el campesino se transforma en receptor económico y, en ocasiones, en trabajador de sus propias tierras, sin posibilidad de decisión sobre ellas. Por lo que se encuentran en peligro los saberes locales históricos de las poblaciones ribereñas así como su cultura lacustre.

Palabras clave: Nueva ruralidad, Chapala, campesinos, tecnología, producción.

\section{Abstract}

This article deals with the process of reappropriation of Lake Chapala, Mexico. In the last decades, soil and agricultural production have been transformed in the municipalities bordering Lake Chapala due to the introduction of export crops through modern systems of production technology. So traditional crops have been decreasing or occurring with greater use of pesticides, fertilizers and agrochemicals. The role of the coastal farmer has also been modified because transnational agribusinesses generate a structure of rent or purchase of soils and plots that they use over a period of years, the owner loses the use of their land in exchange for a safe income. In the current coastal scenario, the peasant becomes an economic recipient and, sometimes, a worker on his own land, with no possibility of decision on them. This is why the local historical knowledge of the riparian populations as well as their lacustrine culture are at risk.

Keywords: New rurality, Chapala, peasants, technology, production.

\footnotetext{
* Doctora en Ciencias Sociales. Profesora investigadora del Centro Universitario de la Ciénega sede Ocotlán, Universidad de Guadalajara, Guadalajara, México. El artículo forma parte de los resultados preliminares de la investigación "Dinámicas socioterritoriales y agua en la Subcuenca Chapala, Michoacán y Jalisco, México. Estudio para la gobernanza y la sustentabilidad del agua", coordinado por Adriana Sandoval Moreno. La investigación está enmarcada en el Programa de Apoyo a Proyectos de Investigación e Innovación Tecnológica (PAPIIT) de la Uiversidad Nacional Autónoma de México con clave IN300915. Correo-e: adrianahg@hotmail.com
} 


\section{Introducción}

México tiene en la Constitución Política de los Estados Unidos Mexicanos de 1917 el marco jurídico y las bases del Derecho Ambiental al establecer en diversos preceptos la comprensión del ambiente, así como las facultades y obligaciones para los distintos órdenes de gobierno. Sin embargo existen procesos económicos, políticos, sociales y ambientales que han impedido una correcta protección, preservación, cuidado y conservación de los recursos naturales. De manera que en los últimos años se han documentado estudios sobre el incremento de la contaminación en cuerpos y cuencas hidrológicas y su impacto en la salud en diversos estados del país, tal es el caso del río Sonora a partir del derrame tóxico del Grupo México en 2015 (Sánchez, 2015). Así como los casos del Río Blanco en el municipio de Tierra Blanca, Veracruz, que en 2015 registraba el mayor número de enfermos por insuficiencia renal crónica (Ferrera, 2015).

El artículo aborda los resultados de investigación sobre el lago de Chapala que además de ser el más grande del país, pertenece a los estados de Jalisco y Michoacán. El objetivo principal es presentar las trasformaciones rurales en la ribera de Chapala debido a la instalación del modelo de turismo residencial, como también de las condiciones impuestas por empresas trasnacionales, aunado al proceso de expansión del turismo en la ribera. El enfoque al lago como cuenca y territorio hidro-social (Swyngedouw, 2009) pone de manifiesto una situación general en sus riberas, así como en sus habitantes, de manera que los resultados se pueden repetir en otras cuencas del territorio nacional, a la vez que confirma problemáticas globales similares en que las cuencas hidro-sociales adquieren relevancia económica, para perder su valor biocultural.

En términos metodológicos, el caso que se presenta tiene un abordaje transdisciplinar para lograr una comprensión de los elementos que intervienen en una problemática compleja como la del lago de Chapala. De manera que integra la visión de regiones hidrológicas en las políticas públicas, como cuenca y territorio hidro-social, sitúa de forma integral su configuración socio-ambiental para poder lograr su conservación, rehabilitación y protección de sus recursos. De este modo también integra la visión de los actores sociales que la conforman y que comparten un escenario interestatal ${ }^{1}$.

El artículo se encuentra estructurado en cuatro apartados principales y las conclusiones; 1) los estudios de regionalización y cuencas en antropología; 2) las cuencas y la región como motor de desarrollo del siglo $\mathrm{XX}$ en México, 3) el territorio hidrosocial de la Cuenca del lago de Chapala y su conformación histórico cultural; 4) la innovación tecnológica y contextos emergentes en la cuenca del Lago de Chapala. Finalmente se presentan las conclusiones del estudio de cuencas hidro-sociales, la innovación tecnológica y la nueva ruralidad para el estudio del lago de Chapala.

\section{Los estudios de regionalización y cuencas en antropología}

De los estudios antropológicos de la primera mitad del siglo $\mathrm{XX}$ que abordan la relación de la sociedad con el medio ambiente, surge la ecología cultural como propuesta teórica metodológica. Dentro de las corrientes de pensamiento que prevalecían en las primeras 
décadas del siglo XX estuvieron el evolucionismo y el relativismo cultural o particularismo histórico. La primera se fundamentaba en el principio de Darwin sobre una evolución histórica, con la visión lineal y única de la historia que postula que todas las sociedades deben pasar por etapas de desarrollo similares. Mientras que en la segunda corriente, Franz Boas, insistía en la importancia de cada cultura y en la inexistencia de leyes universales que rigieran su propio desarrollo (Boehm, 2005).

Tomé (2005) señala cómo durante la segunda década del siglo $\mathrm{XX}$ se generó en las ciencias sociales un proceso de acercamiento a las relaciones entre economía y ecología que, a pesar de ser discontinuo, mostró en la antropología social interconexiones entre los procesos económicos y ambientales. Entre las aportaciones se encuentran los estudios de autores como Franz Boas que se expandieron entre estudiantes, como Julian Steward, y así pudieron formarse en esta escuela. Steward estudiaría con Alfred Kroeber, Robert Lowie y Edgard Gifford, los dos primeros, alumnos de Franz Boas en la Universidad de Columbia; así Steward aprendería sobre el relativismo cultural y el particularismo histórico, y posteriormente se interesaría por los procesos históricos subyacentes a cualquier fenómeno cultural (Tomé, 2005).

Steward (1955) señalaba que todo cambio cultural es el resultado de la interacción entre cultura y medio ambiente, mediante el proceso de la adaptación. Desde la dimensión diacrónica se buscan aspectos socioculturales similares, de regularidades, de las secuencias históricas o tradiciones culturales independientes que expliquen dicha interacción. En la propuesta de Steward, "los procesos adaptativos a través de los cuales se modifica una cultura históricamente construida en un determinado medio ambiente son el proceso creativo y dinámico más importante del cambio cultural" (Steward, 1955: 21). De ahí la importancia de la investigación empírica para la ecología cultural en la comprensión de: "Los rasgos o elementos que intervienen de manera más directa en la obtención de la subsistencia, a saber, los recursos, la tecnología y el trabajo y la interrelación entre ellos, como el núcleo cultural, y donde se genera el cambio cultural" (Idem.: 81).

En México, los estudios de Steward tuvieron influencia en antropólogos como Pedro Armillas, Pedro Carrasco, Ángel Palerm y Eric Wolf en la década de los años cuarenta. Palerm aplicó la metodología de la ecología cultural en proyectos de investigación, mediante la combinación de los métodos de la ecología cultural, el relativismo cultural, el funcionalismo estructural y el marxismo (Boehm, 2005).

En las investigaciones realizadas por Fábregas y colaboradores en la región de los Altos de Jalisco es posible encontrar datos sobre la construcción cultural de un espacio regional. Así, vemos que en los años setenta en dicha región se mantuvo una identidad cultural, a la vez que se aplicó tecnología para "transformar el medio ambiente", es decir, en el cambio de los entornos geográficos para convertirlos en hábitat cultural (Fábregas, 2001:4). De esta forma, encontramos la región cultural:

“...la antropología y de los aportes brindados por técnicas de investigación etno-metodológicas, la región se percibe como un objeto a construir pacientemente desde investigaciones de campo acuciosas, a partir del imaginario que comparte una comunidad respecto del lugar que habita. Tal enfoque se propone dar cuenta de los lazos inter-subjetivos que crean la dimensión regional, los cuales han sido tejidos en la relación histórica entre la población y un territorio dado" (Preciado, Rivère, Ramírez y Pepin-Lehalleur 2005: 15-16). 
Los estudios de la región cultural de los altos de Jalisco recuperan los procesos de las sociedades locales que posteriormente las regionalizaciones administrativas y económicas no tomaron en cuenta. Algunos de esos elementos fueron: la organización local, la construcción cultural, así como la tecnología propia que pueblos y municipios habían desarrollado para la administración, cuidado y preservación de su agua y suelo.

En la década de los 80', Paré (1989) abordó el proceso de deterioro y creciente contaminación de la cuenca del lago de Chapala, como también la organización de los pescadores a través de cooperativas. En Paré (Ibíd.) se encuentran detallados los elementos ambientales, la referencia al desarrollo regional, así como la conformación social que integran al lago, de manera que el lago ya entonces presentaba una situación de conflicto. La importancia del "estudio antropológico y el abordaje desde la investigación participativa" (Idem.: 18) se debe a que es uno de los pocos trabajos que aborda a los pescadores y sus organizaciones como elemento importante de la conformación del lago, principalmente de las propuestas generadas entonces de manera local y organizada.

\section{Las cuencas y la región como motor de desarrollo del siglo XX en México}

Las ciencias sociales y en particular la antropología han venido estudiando la transformación vertiginosa de las sociedades, ahora integradas en una aldea global. La antropología cultural ha evidenciado, desde los territorios, regiones y cuencas la actual utilización de los recursos naturales, así como las nuevas lógicas de interés en los mismos. A pesar de la existencia de estudios antropológicos de los pueblos, el Estado mexicano a través de las políticas públicas ha tomado poco en cuenta el patrimonio biocultural de las regiones históricas y culturales para su conservación.

El estudio de las cuencas en México tiene un antecedente en los planes de desarrollo en el siglo XX, así como en los estudios de las regiones como construcción histórico-social. En la década de los años treinta del siglo $\mathrm{XX}$, en Estados Unidos se elaboró un plan que posteriormente autorizó el Tennessee Valley Authority (TVA). El plan de desarrollo regional integral vinculaba el conjunto de obras hidráulicas con la promoción del bienestar social y económico de los habitantes de cada región. El desarrollo promovido por los gobiernos de Estados Unidos de Norteamérica tuvo un impacto en la integración de las economías regionales y el impulso de las poblaciones, por lo que posteriormente se tomaron como ejemplo en otros países, como en el caso de México.

La política tecnológica y el modelo de integración económica de Estados Unidos de Norteamérica generaron una gran influencia de México como base para la regionalización y vinculación de las cuencas que propuso el TVA. De forma que el gobierno federal impulsó políticas de desarrollo en las grandes cuencas del territorio nacional, mismas que inician hacia la primera mitad del siglo $\mathrm{XX}$ : en la Lerma-Chapala-Santiago, la del río Tepalcatepec, la del río Papaloapan, y el Proyecto Grijalva, principalmente, donde la política del Estado pretendía generar el desarrollo nacional a partir del ordenamiento de los recursos de estas grandes cuencas (Barkin y King, 1986 y Melville, 1997). 
En 1940 se lleva a cabo la consolidación de las macro-regiones funcionales, divididas en: Noroeste, Norte Centro, Noreste, Centro Norte y Occidente, Centro, Golfo, Pacífico Sur y Península de Yucatán, integradas por localidades mayores de 15 mil habitantes. En el caso de la macro-región Centro Norte y Occidente, ésta estaba integrada por Guadalajara, Aguascalientes, San Luis Potosí, León, Morelia, Irapuato, Fresnillo, Guanajuato, Celaya, Colima, Ciudad Guzmán, Zacatecas, Uruapan, Acámbaro y Tepic. En ese mismo tiempo el país llegó a tener estabilidad política y recuperación económica, por lo que se sentaron las bases para el inicio de su desarrollo industrial (Conapo, 1994). De manera que en 1943 se crearon las comisiones de cuencas hidrológicas como parte de la famosa "marcha al mar", con la intención de reubicar la industria y de establecer la frontera agrícola (Durán, Partida y Torres, 1999 y Barkin y King, 1986).

A nivel nacional las diferentes regionalizaciones representaron una división geográfica; seguida de aspectos económicos, como parte del desarrollo planeado que precisó construir sistemas hidrológicos para impulsarlo. Las regionalizaciones tuvieron distintas aplicaciones cuando se establecieron: en el norte del país los agricultores norteños aceptaron de buena gana la construcción de grandes presas para la ampliación de las obras de irrigación. Mientras que en el sureste mexicano se pretendía implantar ese mismo modelo, ahí existía abundancia de agua y la población era menor, ya que de 1930 a 1970 el porcentaje poblacional de los estados de Veracruz, Tabasco, Campeche y Yucatán (Quintana Roo) había disminuido de 12.6 a 11.8 con respecto a la población nacional (Aboites, 2000). La política de regionalización en el país respondía a criterios basados en el desarrollo económico y la modernización de territorios y procesos productivos. A continuación se presenta un cuadro (1) donde es posible observar las diversas regionalizaciones que tuvieron lugar en el país durante la segunda mitad del siglo XX. 
Cuadro 1. Regionalizaciones en la segunda mitad del siglo XX

\begin{tabular}{|l|l|l|}
\hline Responsable & Año & Regiones \\
\hline $\begin{array}{l}\text { Secretaría de Comunicacio- } \\
\text { nes y Transportes }\end{array}$ & 1959 & $\begin{array}{l}\text { Basada en 171 zonas que se agruparon en cinco unidades } \\
\text { regionales: Noroeste, Norte-Centro, Noreste, Centro y Sur }\end{array}$ \\
\hline $\begin{array}{l}\text { Instituto Mexicano de Inves- } \\
\text { tigaciones Económicas }\end{array}$ & 1959 & $\begin{array}{l}\text { En esta obra resultaron siete zonas que son: Noroeste, } \\
\text { Altiplano Nororiental, Central, Pacífico Sur, Golfo-Istmo } \\
\text { y Sureste }\end{array}$ \\
\hline V. Moshbitz & 1961 & $\begin{array}{l}\text { Siete regiones económicas: Centro, Costa del Golfo, } \\
\text { Norte-Pacífico Norte, Pacífico Centro, Pacífico-Centro y } \\
\text { Yucatán }\end{array}$ \\
\hline $\begin{array}{l}\text { División de Hidrología de } \\
\text { la Secretaría de Recursos } \\
\text { Hidráulicos }\end{array}$ & $\begin{array}{l}\text { 37 Regiones Hidrológicas tomando como base la regio- } \\
\text { nalización anterior, la Dirección General de Estudios de la } \\
\text { misma Secretaría dividió al país en 14 regiones mediante } \\
\text { la agregación de dos o más regiones hidrológicas. }\end{array}$ \\
\hline $\begin{array}{l}\text { Comisión Nacional de los } \\
\text { Salarios Mínimos }\end{array}$ & 1963 & $\begin{array}{l}\text { 111 regiones y se considera poco funcional para fines de } \\
\text { planeación. }\end{array}$ \\
\hline $\begin{array}{l}\text { Secretaría de Hacienda y } \\
\text { Crédito Público }\end{array}$ & 1964 & $\begin{array}{l}\text { Esta división demarca las siguientes zonas: Noroeste, } \\
\text { Norte, Golfo Norte, Centro, Occidente, Centro-Golfo, } \\
\text { Pacífico Ístmico y Sureste. }\end{array}$ \\
\hline $\begin{array}{l}\text { Secretaría de Agricultura y } \\
\text { Ganadería }\end{array}$ & 1966 & $\begin{array}{l}\text { En esta se presentan nueve zonas y cada una comprende } \\
\text { varios estados. }\end{array}$ \\
\hline $\begin{array}{l}\text { Universidad Autónoma de } \\
\text { México publicó una regionali- } \\
\text { zación económica elaborada } \\
\text { por Ángel Bassols Batalla }\end{array}$ & 1967 & $\begin{array}{l}\text { Dos divisiones; la primera es una regionalización econó- } \\
\text { mica hecha en 1964, en la que se obtienen ocho grandes } \\
\text { zonas geoeconómicas y 104 regiones. }\end{array}$ \\
\hline $\begin{array}{l}\text { Secretaría de la Presidencia, } \\
\text { a partir del Decreto que creó } \\
\text { la Comisión Nacional de } \\
\text { Desarrollo Regional }\end{array}$ & $\begin{array}{l}\text { Diez regiones, cada una de las cuales se compone de } \\
\text { estados completos. }\end{array}$ \\
\hline
\end{tabular}

Elaboración propia con datos de Mejía Pedrero, 2007. Regionalización e Indicadores Regionales. Manuscrito.

La división territorial generó el crecimiento de las grandes regiones del norte, centro-occidente y sur para aplicar modelos de producción económica "moderna" como los proyectos en las cuencas Lerma-Chapala-Santiago, río Tepalcatepec, río Papaloapan y Proyecto Grijalva, impulsando su desarrollo económico. Así la política del Estado mexicano estuvo dirigida hacia la generación de un desarrollo nacional a partir del ordenamiento de los recursos de estas grandes cuencas (Barkin y King, 1986). El proceso de modernización en el país también transformó el paisaje, lo que produjo ganancias pero también generó sus costos. Entre las primeras están el crecimiento demográfico en los grandes y medianos centros urbanos promovido por las políticas modernizadoras de manera que: "Entre 1920 y 1970 los mexicanos se habían multiplicado más de tres veces: de 14 a 48 millones. La altísima tasa de crecimiento anual era vista 
ahora como un problema mucho más grave que el de la falta de población, según se percibía en la década de 1930" (Aboites, 2000: 144).

El modelo de desarrollo regional impulsado en el país durante el siglo XX generó un manejo del agua dirigido hacia sectores productivos $y$ sociales que sobre explotaron las cuencas y acuíferos mediante uso de tecnología a costo de la sustentabilidad hídrica (Oswald, 2015). Por lo que es también importante señalar que la regionalización a través de cuencas hidrológicas no tomaba en cuenta a las regiones históricas o culturales y su organización local. De manera que la política pública ocasionó el debilitamiento de un tejido social construido a través de la cultura de los pueblos, municipios y regiones. Mientras que las regiones y localidades que se resistieron a la modernización, se les mantuvo aisladas a los servicios mínimos y apoyos gubernamentales durante décadas.

\section{El territorio hidrosocial de la Cuenca del lago de Chapala y su conformación histórico cultural}

El Lago de Chapala cuenta con una longitud de $1,116 \mathrm{~km}^{2}$, capacidad de $8,126 \mathrm{hm}^{3}$ y una profundidad que oscila entre 4 y $6 \mathrm{~m}$ (Conagua, 2011:32) y forma parte de la Cuenca Lerma-Chapala-Santiago. En la segunda mitad del siglo XX el Estado mexicano impulsó el desarrollo y establecimiento de sectores económicos industriales y agroindustriales en la Cuenca, por lo que dicho proceso benefició el crecimiento de cinco de los estados que la integran: Estado de México, Querétaro, Guanajuato, Michoacán y Jalisco. Mientras los cinco estados mantienen la expansión económica, las aguas contaminadas que llegan al lago han impactado en la calidad y cantidad de especies de pesca, como también en fauna y flora ribereñas. Aunado al deterioro en las condiciones de vida de las poblaciones ribereñas de pescadores que históricamente subsisten de la pesca, así como del agua como recurso para sus diarias actividades.

\section{Mapa 1. Municipios que integran la cuenca del lago de Chapala}

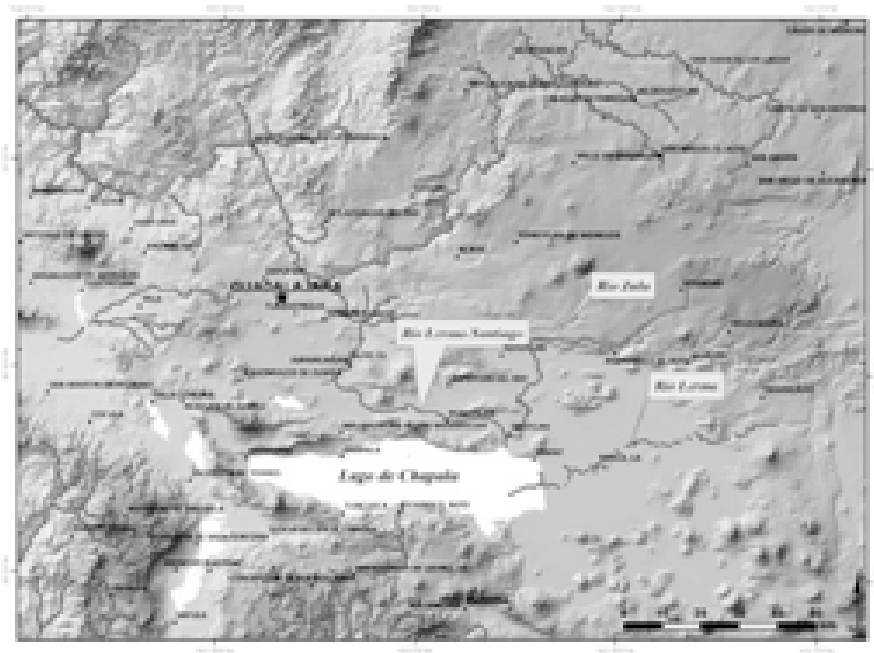

Fuente: Rosario Landgrave, 2008. Instituto de Ecología (Inecol). Xalapa, Veracruz. 
La Cuenca Lerma-Chapala-Santiago ha sido estudiada por autores como Barkin (1988), Boehm (1997; 1998, 1999), Durán y Torres (2002) desde diversos enfoques y con interés especial en temas tales como los problemas agrícolas regionales, su regionalización y su problemática, el abastecimiento del agua a las ciudades y, sobre todo, la relación de las políticas gubernamentales y los cambios efectuados en una de las cuencas más importantes del país.

\subsection{El territorio hidrosocial y su devenir histórico}

El lago de Chapala como territorio hidro social (Swyngedouw, 2009) está compuesto por sociedades históricas que han conformado una cultural lacustre, las cuales han permanecido en su ribera desde tiempos inmemoriales. En la memoria histórica de los pueblos ribereños existe una gran cantidad de símbolos desde los orígenes que se remontan a tiempos inmemoriales, tales como leyendas sobre el origen del lago, la cosmovisión creada a través de elementos mágicos, como también el paso de pueblos originarios que en su transitar de norte a sur, de lo que hoy conocemos como México, se comunicaron, intercambiaron vestigios, rituales, entre otros. Había un tiempo en que la existencia del lago convocaba a vivir un tiempo único en su visita, recorrerlo daba placer a propios y visitantes, comer a la orilla de sus playas pescados recién capturados como actividad diaria o festiva, implicaba un festejo en sí mismo.

La pesca como principal recurso y forma de subsistencia existe desde tiempos inmemoriales en el lago de Chapala, a través de ella, los pueblos se construyeron desde la época prehispánica, mucho antes de la llegada de los españoles en el siglo XVI. Aun cuando se transformaron muchas actividades y territorios durante los siglos XVI al XIX durante la Colonia, la pesca se mantuvo como actividad independiente en la mayor parte de la cuenca. Por lo que a pesar de los cambios económicos, culturales, ambientales y políticos que vivió el país, así como Jalisco y Michoacán, una de las actividades que persistió fue la pesca, que alimentaba a las poblaciones por más pobres que fueran. La fiesta como elemento integral en la vida a través de danzas, actividades recreativas, paseos de los santos patronos, y muchas otras manifestaciones culturales que los pueblos de Jalisco y Michoacán poco a poco construyeron alrededor del lago y la pesca.

La transformación de Chapala comenzó a partir de la desecación del $30 \%$ del lago a inicios del siglo $\mathrm{XX}$, en cuyo proceso participaron autoridades e inversores para generar nuevas formas de utilización del suelo y agua que desde entonces impactan su cuenca. De manera que municipios como La Barca en Jalisco y Venustiano Carranza, Briseñas, Sahuayo en Michoacán fueron privados de la pesca como principal sustento y forma de vida. Por lo que el siglo XX permeó en gran parte de las localidades ribereñas, de manera que actividades económicas, comerciales, turísticas, entre otras se fueron insertando hasta transformar sus territorios, en particular el municipio de Chapala, principal lugar con atractivo turístico.

3.2. Los guardianes del lago ante un problema ambiental creciente

En las diversas poblaciones ribereñas se encuentran fantásticas historias del origen del lago. En Mezcala narran como: 
"La creación de la laguna de Chapala fue a partir de un castigo divino, dirigido al dueño de esas tierras por negar el alimento y golpear a la máxima deidad disfrazado de pordiosero, todo a partir de una gran lluvia que cayó sobre sus tierras (el actual lago de Chapala), convirtiendo así, las monedas de oro en carpas, las monedas de plata en tilapias, los puercos en bagres, etc." (Sandoval, Corona, Ávila, Moreno, 2016: 24-26).
Estas narraciones ofrecen elementos sobre la visión religiosa de cómo se creó la isla de Mezcala y el chipotito que se encuentra a su lado, para contar con una imagen completa de la creación del actual lago de Chapala. A consecuencia de desobedecer las órdenes de Dios vestido de pordiosero, de irse y no voltear ante los ruidos que pudieran escuchar. "Ya en la noche salieron la señora con su viejo para el cerro y que empiezan a oír ruidos fuertes, feos y voltearon y dicen que se volvieron rocas" (Hernández, 2000).

\section{Fotografías 1 y 2. Guardianes del lago, el viejo y la vieja}
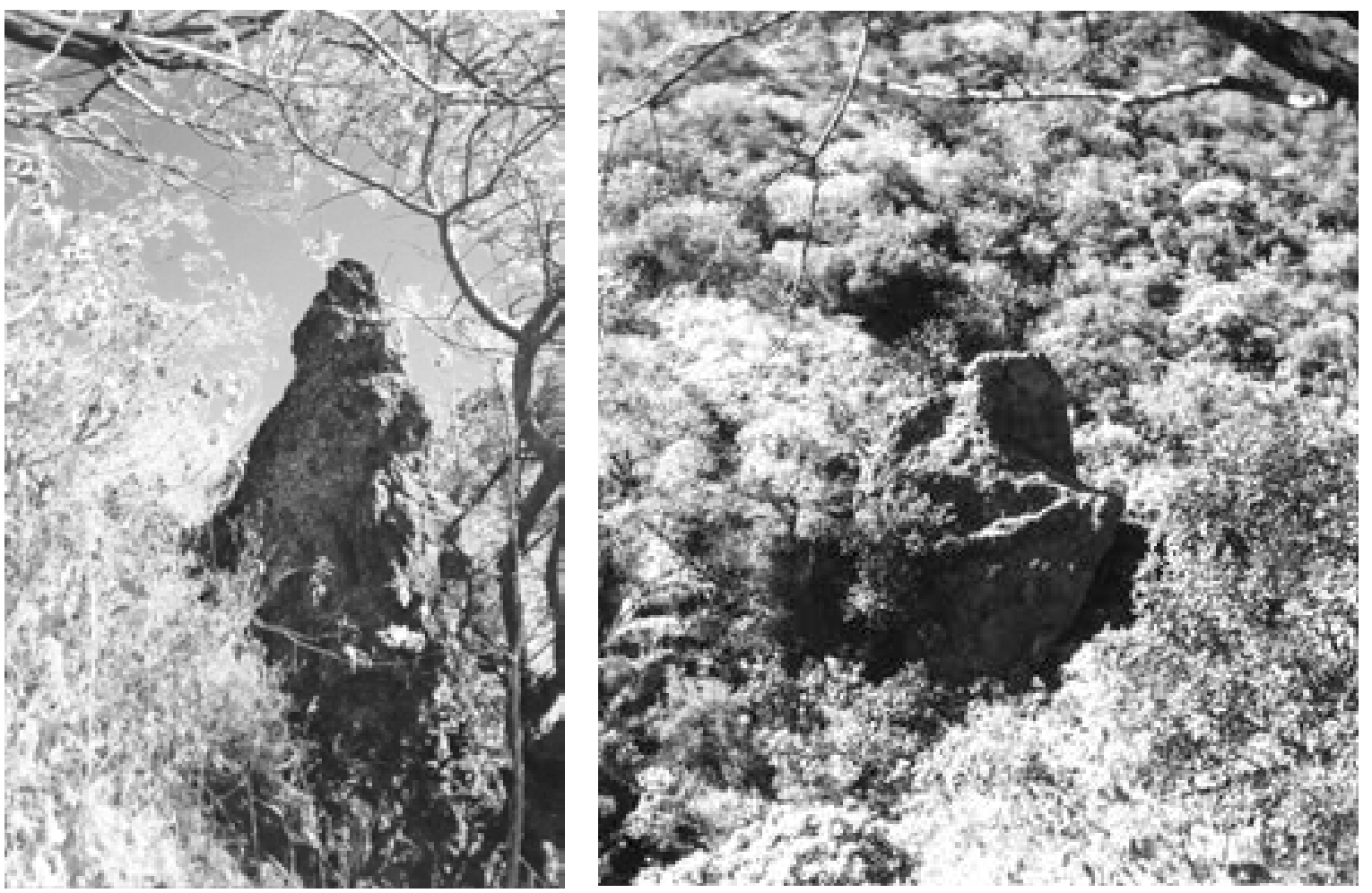

Fuente: Propia.

Fotografías tomadas en la ribera del lago. 2000. 
Las fotografías 1 y 2 muestran al Viejo y la Vieja, dos de los elementos simbólicos más importantes en Mezcala, en la percepción de los habitantes ellos son los proveedores míticos del agua suficiente y de buena calidad. Su conformación es rocosa, la Vieja mide aproximadamente 30 metros de altura, con la forma y contorno de mujer robusta sentada, mientras el Viejo que cuenta con alrededor de 3 a 4 metros tiene una forma delgada. Los habitantes de Mezcala comentan que se acostumbraba pedir agua a los guardianes en peregrinaciones los años que no llovía mucho, las personas iban descalzas y cargando bules de agua se dirigían al cerro con velas y santos cantando y orando todo el camino a la Vieja y el Viejo (Hernández, 2000: 142-144).

Otro de los guardianes antiguos del lago es el Chan del agua, el cual "es el encargado de cuidar y preservar la vida de los animales que habitan en las aguas de este lago.... Puede tomar forma de cualquier animal y aparece cada que la laguna se encuentra en sequía" (Sandoval, et al., 2016: 70-72). Existen muchas más historias sobre la aparición del Chan del agua, como por ejemplo cuando lo mataron, o sobre sus "cacas", pero sobre todo de las innumerables veces que salvó al lago de la sequía. Una de las narraciones más recordadas fue la historia del chan contra la virgen de Zapopan, en la cual la población de la ribera se encuentra dividida en la decisión, sobre quién salvó el lago de la sequía de 1952.

\subsection{La virgen de Zapopán y los nuevos guardianes del lago}

En las leyendas sobre las deidades del agua, se cuentan dos versiones sobre quién salvó el lago de la terrible sequía de 1952, por una parte se tiene la alusión de que a unos pescadores se les apareció el Chan del agua para avisarles que salieran rápidamente del lago porque el agua iba a subir de inmediato, este grupo supo rápidamente de quien se trataba así que decidieron salir rápido, en ese momento el cielo se nubló y comenzó a llover llevando de este modo el lago. Pero la otra versión nos cuenta que ese mismo día hubo una peregrinación de Chapala donde trajeron a la virgen de Zapopán para que la lluvia llegara y así fue cómo solo unos de la comunidad creyeron la versión del Chan del agua y los demás tuvieron la devoción por la virgen desde entonces (Idem., 2016). 
Fotografía 2. La virgen de Zapopán en su visita a Mezcala

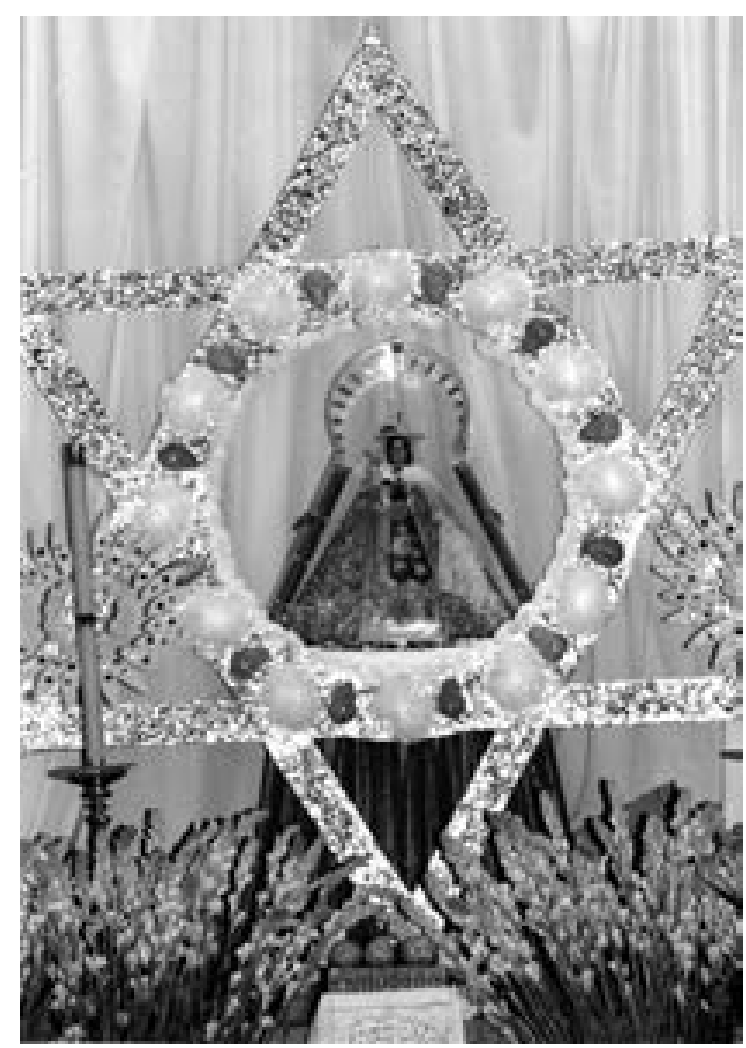

Fuente: Propia.

Altar del templo de Mezcala de la Asunción. 2000.

En la actualidad la virgen de Zapopán ha sido nombrada la guardiana o generala de todo Jalisco así como de las localidades del lago, por lo que realiza una visita por los municipios de la ribera al menos una vez cada año para garantizar su protección y la temporada de lluvias. Las actividades que se realizan durante las visitas de la virgen en cada localidad son principalmente las siguientes: el comité organizador la recibe en la entrada del poblado donde la virgen y los habitantes realizan un recorrido por las calles principales, las casas están adornadas con papel picado en colores azul y blanco, con formas diversas. Durante el trayecto a la iglesia principal se lanzan cohetes, mientras se van cantando y/o rezando. Al llegar al templo, se lleva a cabo una misa o eucaristía, con rosarios, cantos y oraciones, finalmente al día siguiente se lleva a cabo otra misa de agradecimiento para la visitante, se le despide y así continúa con su peregrinación hacia el siguiente poblado (Hernández, 2000).

En la primera década del siglo XXI se desarrolló una nueva protección internacional del lago de Chapala por parte de grupos civiles y autoridades municipales, conocida como la declaración de sitio RAMSAR, y desde el año 2009 se encuentra en la lista de "Humedales de Importancia Internacional” con el número 1973. 
A pesar de la relevancia de la declaratoria así como de la responsabilidad adquirida por los tres niveles de gobierno, en términos locales los programas de protección de los municipios de Chapala no han aplicado la protección que requiere su designación. En cuanto al nivel federal y estatal, los gobiernos de los cinco estados corresponsables de las aguas que llegan a Chapala poco se preocupan por la calidad de agua que llega al lago y vierten sus aguas a través del río Lerma, que recorre diversos estados del centro de país como Estado de México, Querétaro, Guanajuato, Michoacán y Jalisco.

\section{Innovación tecnológica y contextos emergentes en el Lago de Chapala}

En los años recientes se ha promovido la reorganización del territorio de tres municipios ribereños, Poncitlán, Ocotlán y Jamay, en la Zona Metropolitana de Ocotlán. A pesar que el diseño del ordenamiento territorial en proceso sostiene la necesidad de generar un desarrollo sustentable en la transformación del territorio de los tres municipios, el lago de Chapala no aparece en los proyectos prioritarios, es decir, una relación entre la transformación y los impactos en la cuenca. Es posible que en el desarrollo metropolitano no se encuentren equilibrados los beneficios económicos que se podrán generar a partir del desarrollo de la zona metropolitana con los impactos ambientales, sociales y culturales de los pueblos ribereños y habitantes de los tres municipios.

En la segunda mitad del siglo $X X$ en el Lago de Chapala se establecieron nuevos capitales para la inversión lo que ha generado la reestructuración del paisaje ribereño rural a paisajes adaptados para poblaciones internacionales. Sandoval (2016) señala que la: "cuenca del lago de Chapala es un espacio diverso en cuanto a la composición de su población y las condiciones de grupos sociales y económicos que la integran. Los municipios con mayor número de población total son Ocotlán, Poncitlán, Chapala y Jocotepec, todos ubicados en la zona norte del lago, la que corresponde al estado de Jalisco y ha sido la más atractiva para inmigrantes extranjeros e inversionistas del agro" (Sandoval, 2016: 6). A continuación se presenta una tabla con el desglose de la población de los diferentes municipios que conforman la ribera del lago. 
Tabla 1. Número de habitantes de la cuenca del lago de Chapala 2010

\begin{tabular}{|c|c|c|}
\hline MUNICIPIO & \multicolumn{2}{|l|}{ AÑO 2010} \\
\hline \multicolumn{3}{|c|}{ ESTADO DE JALISCO } \\
\hline Chapala & 48,839 & \\
\hline Jamay & 22,881 & \\
\hline Ocotlán & 92,267 & \\
\hline Poncitlán & 48,408 & \\
\hline Tizapán el alto & 20,847 & \\
\hline Tuxcueca & 6,316 & \\
\hline Jocotepec & 42,164 & \\
\hline SUBTOTAL ESTADO DE & & 281,722 \\
\hline \multicolumn{3}{|c|}{ ESTADO DE MICHOACÁN DE OCAMPO } \\
\hline Venustiano Carranza & 23,455 & \\
\hline Cojumatlán de Regules & 9,980 & \\
\hline Briseñas & 10,653 & \\
\hline SUBT & TADO DE MICHOACÁN & 44,088 \\
\hline
\end{tabular}

Fuente: Hernández, A. (2017). El lago de Chapala y su importancia ambiental. Reflexiones sobre el patrimonio biocultural de Jalisco y Michoacán, (INEGI, 2010 en Hernández, 2017: 135-148).

Un atractivo particular que ofrece el lago de Chapala son los nacimientos de aguas termales en toda su ribera particularmente en la localidad de San Juan Cosalá, municipio de Jocotepec, Jamay y Ocotlán. En tiempos recientes los servicios se han expandido en hoteles integrados a los balnearios como el Hotel balneario San Juan Cosalá, Termal Cosalá, Monte Coxala, entre otros. La tecnología estética brinda también una gran diversidad de centros de sanación, spa's o centros curativos y de belleza integral, que ofrecen diversas técnicas termales curativas a través de temazcales modernos, vapores, inhaladores, masajes, entre otros para ofrecer un proceso de limpieza integral entre ellos. Ejemplo de lo anterior son el Chante Hotel-Spa, Total Body Care Spa de
Ajijic, Monte Coxala Spa Ecológico en San Juan Cosalá, entre otros (Hernández, 2016).

En los municipios de Ocotlán y Jamay de la ribera norte del lago se ha generado otro concepto de centros recreativos, en Jamay se localiza "Corral grande" balneario que ofrece alrededor de 20 albercas de todos tamaños, toboganes, áreas de juegos, áreas de descanso, etc. en Ocotlán cuenta con balnearios como: San Gerónimo, El Hongo, Albercas Serrano, que ofrecen una diversidad de albercas, áreas de juego y descanso.

Un paisaje que se ha ido expandiendo en municipios como Tizapán el alto, Tuxcueca y Jocotepec es la instalación de sombreados 
plásticos para el cultivo de frutos rojos como zarzamoras, arándanos, entre otros. La tecnología juega un papel fundamental para el proceso productivo debido a los cuidados que requieren los cultivos.

\section{Fotografía 6. Granjas de berries en Tizapán el alto.}

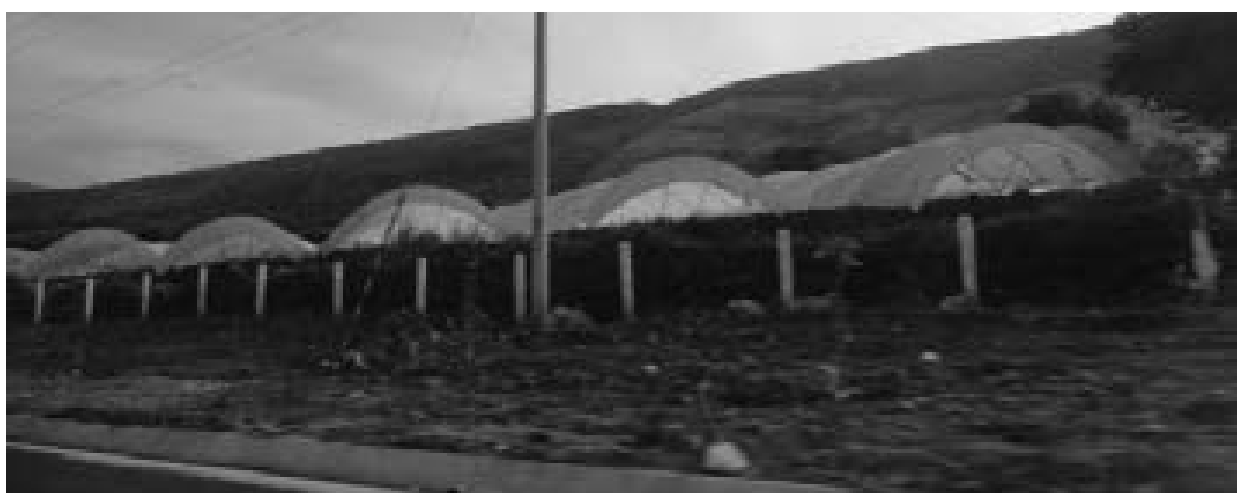

Fuente: Adriana Hernández García. Mayo 2015.

Tizapán el alto, Jalisco.

Las agro empresas de berries tienen patrones de uso de las tierras mediante convenios con los dueños en renta fija por diversos años, que van desde 5 en adelante. El cambio de uso de suelo incluye también la inversión de sistemas de riego tecnificado y permanente, a diferencia de los cultivos tradicionales que generalmente utilizaban riego de temporal. Debido a que la producción de berries es permanente, el uso del suelo de intensivo, lo que provoca la sobreutilización de suelos en poco tiempo.

Los nuevos usos recreativos y agroindustriales de la ribera del Lago de Chapala son dos ejemplos de una nueva apropiación de los territorios que hasta hace décadas pertenecían a campesinos y pescadores artesanales. La nueva ruralidad en el área norte de Chapala se expresa en la integración de nuevos actores económicos, sociales y culturales que muestran una ribera del lago transformada y con gran oferta para población internacional.
4.1. Escenariosemergentes ribereños: Ios impactos en la salud y la resistencia de los habitantes frente a la transformación de su territorio

Desde el enfoque hidro social Swyngedouw (2005) señala que las transformaciones del territorio se generan por clase, género, étnico u otro conflicto de poder, así como los impactos hacia los grupos pobres y vulnerables son principalmente por falta de servicios básicos, como por ejemplo en relación a la salud. Actualmente en el lago de Chapala se viene desarrollando un mayor impacto a través de los cambios en su territorio hidro social y habitantes ribereños. De manera que se observan situaciones de desigualdad entre los habitantes de grandes ingresos económicos, hacia los pueblos ribereños tradicionales que se encuentran en riesgo de perder los ingresos que les proporcionaban las actividades económicas como la pesca y la agricultura. 
Una zona del lago de Chapala que se ha mantenido en resistencia desde tiempos de la Colonia es la conformada principalmente por los pueblos de Mezcala, San Pedro Itzicán, Agua Caliente y Chalpicote. De manera que han quedado históricamente aislados del desarrollo y hasta de los servicios básicos que disfrutan otros habitantes del lago. Entre los pueblos ribereños se pone en entredicho que la verdadera escasez de agua no reside en la ausencia física de agua, sino en los recursos monetarios como en la influencia económica y política en el control por los territorios y recursos naturales. Por otra parte, el desencuentro entre los planes regionales y la mirada integral se mantienen en la actualidad así como los conflictos entre los usuarios históricos y emergentes. "Los procesos de cambios socio-ambientales no son nunca ecológicamente neutrales. Estos resultados en condiciones bajo trayectorias particulares de cambios socioambientales subestima la estabilidad o coherencia de algunos grupos sociales o ambientales, mientras la estabilidad de otros se ha mejorado (Swyngedouw, 2009).

\subsection{La resistencia y la salud en los habitantes ribereños del lago de Chapala}

Acontecimientos históricos como la defensa de su territorio en el movimiento de la Independencia del país durante el siglo XIX, la conformación en comuneros en la etapa posrevolucionaria, así como la recuperación del área del Comal en años recientes, dan fe de la resistencia permanente que los habitantes ribereños han mantenido con autoridades civiles locales, estatales y federales. Sin embargo también se han presentado escenarios contrastantes a las políticas públicas, los que indican una desigualdad en el acceso al agua y otros servicios básicos en localidades cercanas al municipio de Chapala como San Pedro, Agua Caliente y Mezcala. El incremento en los niveles de contaminación del lago han ocasionado que los habitantes ribereños con menos recursos ya no consuman agua directamente de la orilla, aunado al poco o nulo servicio de agua potable por parte de las autoridades correspondientes, ha generado el consumo de agua con altos niveles de contaminación (Torres, 2017). María Díaz Santiago señala que les pidieron una cooperación de 13 mil pesos para hacer investigación de campo, y ver dónde se podía hacer un pozo. Apenas esta semana, personal no identificado por alguna dependencia, fue a la comunidad para avisarles que era imposible hacer un nuevo pozo:

\footnotetext{
"Pero nos dijeron que nos iban a conectar a un pozo que ya no tiene agua. No va alcanzar, yo no sé por qué no nos conectan". Sin embargo, es la misma comunera quien afirma que el agua caliente que brota del suelo no es buena para la salud, "tenemos a muchas personas enfermas de los riñones, porque no hay agua buena" (García, 2014 en Hernández, 2016).
}

A inicios del 2017, el rector general de la Universidad de Guadalajara en conferencia de prensa, señaló que la situación en Agua Caliente y San Pedro Itzicán es "la punta del iceberg de un problema ambiental en Jalisco" (Alatorre, 2017). Por lo que puede ser un indicador de una realidad presente en toda la cuenca del lago de Chapala que aún no ha sido identificada. La Comisión Nacional del Agua (CONAGUA), principal instancia en el manejo del agua en México, asegura que la contaminación del lago no es severa. Por su parte, los organismos municipales, regionales y estatales, mantienen escepticismo respecto a las causas del problema de salud. 
4.3. Otras voces locales sobre la contaminación del lago de Chapala

En los últimos tiempos se han realizado estudios relacionados con el estado del agua del lago de Chapala con información y resultados preliminares y parciales para las autoridades de los diferentes niveles de gobierno. Mientras que para los habitantes, pescadores, agricultores y ganaderos es claro que el agua del Lerma es una importante fuente de contaminación y enfermedad. Algunos de los testimonios que se han obtenido por parte de los habitantes son:

"Porque está contaminado, antes no había contaminación, había otras especias de especies de los que hay ahorita, antes no había mojarra o tilapia, esa pues después la sembraron" (Entrevista a David Ortega, 2016).

"Ocotlán es un pueblo de mueblerías, entonces hay muchos talleres donde se produce el herraje del mueble, no hay un lugar en todo Ocotlán donde se tire el desecho, todo ese desecho va directo a la laguna y según yo es radioactivo y lo poco que yo sé con lo que se hace el herraje de los muebles, todo eso va a dar a la laguna" (Entrevista a Javier Salgado, 2016).

Mientras el Sr. Ramón señala sobre el cambio del agua del lago:

\footnotetext{
"Estábamos bien, todo estaba muy limpio, desgraciadamente el progreso hemos ido acabando con todo, han pasado presidentes de la Republica y estamos pugnando, verdad, porque nos regresen nuestra agua, porque como no hay agua, más que nadie Guanajuato se ha aprovechado en construir más presas que barbaridad, Guanajuato, el Alto Lerma que es el estado de México, Querétaro y parte de Michoacán entonces lo que le sobra es lo que nos dejan pasar" (Entrevista Ramón Rodríguez, 2016).
}

En la opinión del Sr. Javier el proceso de disminución del lago tiene entre otras causas:

\begin{abstract}
"También hemos notado que la han ido aterrando, hay empresas grandes que desconozco como han conseguido los permisos para irla aterrando, hay una cota a la 96 donde tiene un límite la laguna y yo sé que aguas nacionales por ahí tiene una ley que especifica que no debe de haber ni fincas ni cerca algo así pero es todo lo contrario, la laguna la van recorriendo así hacia adentro, la están aterrando con graba y mucho no creas que poquito" (Entrevista a Alfredo Molina, 2016).
\end{abstract}

A pesar de que para los habitantes ribereños la contaminación principal del lago de Chapala llega a través del río Lerma, en los programas y planes de ordenamiento y desarrollo territorial de Jalisco o Michoacán no se encuentran medidas de protección y defensa hacia los estados de Guanajuato, Querétaro o el Estado de México. Sin embargo, son los habitantes ribereños y las sociedades ribereñas que ven sus tierras, la riqueza del paisaje y los recursos del lago, transformarse en escenarios donde disminuyen sus posibilidades de participación en un territorio hidro social en constante movimiento.

\section{Conclusiones}

El lago de Chapala es un reto para los estudios sociales contemporáneos y en particular para las investigaciones antropológicas, debido a la gran diversidad de escenarios locales sobre la cultura lacustre que la conforman. Es a través de una mirada cualitativa que se puede conocer la importancia histórica y actual de los saberes locales sobre la conservación del lago, los cuales aun se encuentran presentes en las comunidades. Reconocer la pesca como actividad económica y cultural desde tiempos 
inmemoriales en los pueblos ribereños, es indispensable para generar propuestas integrales para su conservación.

El lago de Chapala es una cuenca y territorio hidro social que habitan más de trescientos mil ribereños e implica más que una reserva hídrica para las zonas metropolitanas de Guadalajara y Ocotlán. La mirada antropológica permite centrarse en la riqueza ecológica, humana, cultural, histórica, que conforman al lago más grande de México hasta el día de hoy. La subordinación de las poblaciones de pescadores y agricultores tradicionales del lago genera mayores índices de desigualdad, pobreza, enfermedad y muerte en los pueblos ribereños pobres. Mientras que en las playas o riberas de mayores ingresos económicos, las poblaciones desplazadas forman parte del sector trabajador para los nuevos "dueños de Chapala".

La cuenca Lerma-Chapala-Santiago y sobre todo el lago de Chapala son un ejemplo de las transformaciones que los tres niveles de gobierno promovieron durante el siglo XX. Las iniciativas modernizadoras que se impulsaron desde las primeras décadas desecaron el $30 \%$ del lago y mutilaron su cauce natural. El lago se convirtió en el receptor de las aguas contaminadas que los planes de desarrollo de las regiones hidrológicas impulsaron en los estados de México, Querétaro, Guanajuato, Michoacán y Jalisco para usos industriales, de vivienda y agroindustriales. En la actual propuesta de decretar zonas metropolitanas como nueva política pública a nivel nacional debe ser aplicada a partir de la conformación hidro social en los estados de Michoacán y Jalisco, y en particular en el lago de Chapala para no recurrir a los errores de desarrollo del siglo XX. En la zona metropolitana de Ocotlán el proceso de transformación de la cuenca y territorio del lago de Chapala muestra una separación de las actividades que se realizan para transformar su territorio con los posibles impactos que afectan sus recursos y cuenca, como los ordenamientos territoriales que promueven mayores impulsos al turismo mediante la ampliación de malecones, zonas residenciales, zonas industriales, etc.

La nueva ruralidad del lago de Chapala se encuentra integrada por una diversificación de actores internacionales que van apropiándose de la ribera mediante actividades productivas de exportación, así como en la multiplicación de zonas habitacionales que ofrecen una vida pacífica y agradable a la orilla del lago más grande de México. En el estudio de la cuenca del lago de Chapala como territorio hidro social se observan los nuevos procesos socio-ambientales junto con el surgimiento de conflictos por un territorio en disputa. La defensa del territorio y sus actividades tradicionales la han realizado los habitantes locales ante el reto de la integración a los cambios e ir perdiendo la autonomía de sus recursos y procesos locales, o bien la resistencia bajo el peligro de la violencia o el despojo. Un caso emblemático en la cuenca del lago de Chapala es el de las comunidades indígenas de Mezcala y San Pedro Itzicán, que hasta la actualidad mantienen un sistema autónomo de autoridades comunales y ejidales que mantienen una autonomía respecto de no aceptar los cambios propuestos, de manera que se mantuvieron aisladas y privadas de los servicios básicos. 


\section{Notas}

\footnotetext{
${ }^{1}$ Los sitios Ramsar son acuerdos intergubernamentales sobre la protección del medio ambiente, a través de un tratado entre países y organizaciones no gubernamentales preocupados por la pérdida de hábitats de humedales, se adoptó el nombre de RAMSAR por el nombre de la ciudad iraní de Ramsar en la década de los años 70 .
}

\section{Referencias bibliográficas}

Aboites, L. (2000). "Optimismo Nacional: Geografía, ingeniería hidráulica y política en México (1926-1976)". En Brígida VON Mentz (coord.), Luis Aboites, María Bertely, Yolanda Montiel. Identidades, Estado nacional y globalidad. México, siglos XIX y XX. México: CIESAS. Colección Historias.

Alatorre, K. (2017). Encuentran metales pesados en habitantes de Poncitlán. Disponible en la página web de la Universidad de Guadalajara. Fecha de consulta: 30 de enero del 2017.

Barkin, D. \& T King. (1986). Desarrollo Económico Regional. (Enfoque por cuencas hidrológicas de México). Siglo veintiuno editores.

Barkin, D. (1988). "Cambios tecnológicos, dependencia y transformaciones de la sociedad rural". En Jorge Zepeda Patterson (ed.) Las Sociedades Rurales Hoy. Michoacán: El Colegio de Michoacán/CONOCí.

Boehm, B. (2005). "Historias del agua en zonas de alta inversión para el desarrollo en el centro-occidente de México". En Juan Manuel Durán, Martín Sánchez y Antonio Escobar (eds.). El agua en la historia de México. Guadalajara: CUCSH-Universidad de Guadalajara. (1997). "El enfoque Regional y los estudios regionales en México: Geografía, Historia y Antropología”. Relaciones, № 72.

Boehm, B. \& Sandoval, M. (1998). "La transformación cultural de un paisaje palustre: tiempos largos en la Ciénega de Chapala". Revista Estudios del Hombre, № 10.

(1999). "La sed saciada de la ciudad de México y la Nueva Cuenca Lerma-Chapala-Santiago. Un ensayo metodológica de lectura cartográfica". Relaciones. Estudios de Historia y Sociedad, 80, otoño. Vol. XX.

Comisión Estatal del Agua (CEA) Jalisco. (2016). Disponible en: http://www.ceajalisco.gob.mx/cuencas/lagochapala.html Fecha de consulta: 12 de agosto de 2016.

Comisión Nacional del Agua (CONAGUA). (2011). Estadísticas del agua en México. México: Secretaría de Medio Ambiente de Recursos Naturales.

Consejo Nacional de Población (CONAPO). (1994). Evolución de las ciudades en México 1900-1990. México: Consejo Nacional de Población/Fondo de Población de las Naciones Unidas.

Durán J. \& Torres, A. (2002). "La crisis ambiental en el lago de Chapala y el abastecimiento de agua para Guadalajara". En Los estudios del agua en la Cuenca Lerma-Chapala-Santiago. El Colegio

\begin{abstract}
${ }^{2}$ Entrevistas realizadas: Entrevista a Ramón Rodríguez. Jamay, Jalisco. Septiembre del 2016. Entrevista a Javier Salgado. Ocotlán, Jalisco, Septiembre, 2016. Entrevista a David Ortega Jamay, Jalisco. Septiembre del 2016. Entrevista a Alfredo Molina Jamay, Jalisco. Septiembre del 2016.
\end{abstract}

de Michoacán/ Universidad de Guadalajara.

Dirán, J., Partida, R. \& Torres, A. (1999). "Cuencas hidrológicas y ejes industriales: el caso de la Cuenca Lerma-Chapala-Santiago". Relaciones. Estudios de Historia y Sociedad. 80, otoño, Vol. XX.

Guzmán, M. (2003). "Chapala, una crisis programada”. PVEM Grupo Parlamentario. Cámara de Diputados LVIII Legislatura. Guadalajara, Jalisco.

Fábregas, A. (2001). "Sociedad y Medio Ambiente: una revisión antropológica”. El Colegio de Jalisco (Ponencia).

Ferrera, L. (2015). "Enfermos renales en Tierra Blanca 10 veces más que en el país". Noticieros Televisa. 27 de julio del 2015. http:// noticieros.televisa.com/mexico-estados/1507/problemas-renalescausan-mas-muertes-tierra-blanca-veracruz/ Fecha de consulta: el 17 de julio del 2016.

Hernández, A. (2000). "El Pueblo De Mezcala y los Efectos De La Degradación Ambiental En El Lago De Chapala”. Tesis de Maestría. Centro de Investigaciones y Estudios Superiores en Antropología Social. Guadalajara, Jalisco.

(2016). "El lago de Chapala y su importancia ambiental. Reflexiones sobre el patrimonio biocultural de Jalisco y Michoacán". Revista Estudios de la Ciénega. № 34.

Mejía, L. (2007). Regionalización e Indicadores Regionales. Manuscrito. 12 páginas.

Melville, R. (1997). "El concepto de cuencas hidrográficas y la planificación del desarrollo regional". En Hoffmann. O. \& Salmerón, F. (Coords.), Nueve estudios sobre el espacio. Representación y formas de apropiación. México: CIESAS/ORSTOM/Institut Francais de Recherche Scientifique pour le developpement en Cooperation. México.

Oswald, Ú. (2015). "El agua como factor crítico del desarrollo regional”. En Pérez Correa, F. (coord.) Gestión pública y social del agua en México. México, D. F.: Universidad Nacional Autónoma de México.

Paré, L. (1989). Los pescadores de Chapala y la defensa de su lago. Guadalajara: Instituto Tecnológico de Estudios Superiores de Occidente (ITESO), El Colegio de Jalisco. Universidad Nacional Autónoma de México (UNAM).

Preciado, J., Rivère H., Ramírez, L. \& Pepin-Lehalleur, M. (coords.) (2005). Territorios, Actores y Poder. Regionalismos emergentes en México. Universidad de Guadalajara/Universidad Autónoma de Yucatán. 
Sánchez, D. (2015). “Grupo México afectó a 75 niños y 49 ancianos por derrame en río Sonora". Disponible en Excelsior, 11 de junio del 2015, sección Estados. http://www.excelsior.com.mx/ nacional/2015/06/11/1029049. Fecha de consulta: 17 de julio del 2016.

Sandoval, A. \& Hernández, A. (2013). "Cambios socioambientales y crisis de los pescadores en el Lago de Chapala, México". Revista Ambiente y Desarrollo. № 32 .

Sandoval, A. (2016). Ponencia: "La subcuenca del Lago de Chapala y las dinámicas socioterritoriales", en la mesa: Estudios y reflexiones teóricas sobre cuencas y territorios hidroociales. En el marco del $4^{\text {to }}$ Encuentro de la Red de Investigadores Sociales Sobre el Agua, edición Internacional. Tonalá Jalisco. 16 de marzo de 2016.

Sandoval, L., Corona, C., Ávila, K. \& Moreno, I. (2016). Los espacios de la memoria cuentos, leyendas y relatos históricos de la ciénaga de Chapala. México: Página Seis.

Steward, J. (1955). Theory of culture change. The methodology of multilinear evolution. University of Illinois Press. Londres. Urban Chicago.
(1955). Teoría y práctica del estudio de áreas. Washington, D.C.: Unión Panamericana.

Swyngedouw, E. (2009). "The Political Economy \& Political Ecology of de Hydro - Social Cycle". Journal of Contemporary Research \& Education. Issue 142.

Tomé, P. (2005). "Ecología cultural y antropología económica". Relaciones, № 102.

Torres, G. (2017). San Pedro Itzicán, enfermar en condiciones de pobreza. Reportaje del Noticiero Notisistema. 18 de abril del 2017. Disponible en: http://www.notisistema.com/noticias/san-pedro-itzicanenfermar-en-condiciones-de-pobreza-extrema/ Fecha de consulta: el 19 de abril del 2017.

UN Water. (2015). Un objetivo global para el agua POST-2015. Síntesis de las principales conclusiones y recomendaciones de ONU-AGUA. Aprobado por ONU-AGUA en su vigésima reunión el 27 de enero del 2014. Disponible en: http://www.un.org/spanish/ waterforlifedecade/pdf/findings_and_recommendations_post2015_ goal_water_spa.pdf 